\title{
Abstracts
}

\section{Older Women and Housing}

Sheila Peace

Whilst more attention is being paid to the needs and circumstances of older women, the particular issues of older women and their housing, and the use of gender in determining the housing needs of older people, are as yet little researched. Recent work by Brion and Tinker ${ }^{1}$ and the Matrix collective concerning women and housing/environment ${ }^{2}$ bring into sharp focus the contrast between women's interest and involvement with their homes and their lack of influence in terms of planning, design and the control of property. The traditional dependent status of women and the importance of the nuclear family have been key factors in determining both the type and tenure of housing that they occupy.

L. Coleman and S. Watson, Older women: housing issues and perspectives. Australian Journal on Ageing, 4 (3) (1985), 3-8.

The article by Coleman and Watson reports on the housing circumstances of seventy women aged over 6o years, and living on their own in Sydney, Canberra and Queanbeyan. Particular emphasis is paid to the 'impact of women's social and economic status on their housing experiences in old age' focusing on four major housing alternatives homeownership, public and private rented accommodation and retirement villages. A majority of the women were widowed $(74 \%)$, over 70 years of age $(64 \%)$, Australian or European born and in good health. Lengthy interviews were undertaken concerning current housing situation, income, transport, access to services and social networks, as well as housing, employment and family histories.

Findings are discussed in relation to the four types of accommodation outlined above. In terms of homeownership, the study found that what is often seen as security can in reality feel very insecure. For women living alone on fixed incomes problems of maintenance and repairs as well as the responsibility for rates and other bills were very pressing. The dependence of wives on their husbands for home maintenance meant that many widows now lived in housing that was in a poor state of repair. Women reported feeling very vulnerable, especially if they had to bring in outsiders to undertake repairs. The payment of high 
corporate maintenance fees by those living in blocks of flats was also raised by respondents. Here the wishes of owners of different age groups were sometimes at odds. It appeared that many respondents lacked the knowledge or the confidence to organise solutions to their problems and the authors highlight the need for both organised home repair schemes and easy access to information on housing alternatives.

In contrast to the homeowners, those living in retirement villages reported very different problems as the 'change of accommodation necessarily implied a change of lifestyle'. Of interest here are the issues raised by different types of institution. Those reporting least satisfaction with their accommodation experienced least autonomy and choice - a finding echoed in recent work in British old people's homes. ${ }^{3}$ These women had frequently been 'persuaded' to move either by family or doctor into accommodation where there had been no trial period and where an initial deposit of $\$ 10,000$ was not refundable if the individual decided to move. They lived in bedsit accommodation without the opportunity either to cook for themselves or to entertain visitors who could not stay overnight. The authors comment on the domestic role of women which is denied in such settings. ${ }^{4}$ They contrast these findings with those of satisfied respondents living in another retirement village in one-bedroom, self-contained units. Here residents cared for themselves as far as possible but benefited from the knowledge that help was available if necessary and they did not have to worry about maintenance.

Very little is known about the circumstances of older people living in the private rental sector of large cities in Britain and yet one suspects the findings from this Australian study have important parallels. The private rental sector appeared the least satisfactory form of accommodation for older women. Rents in inner city areas are escalating, and the study reports on older women living in crowded sub-standard accommodation in high-risk areas, often faced with the threat of eviction. Yet, in spite of the insecurity of tenure and poor conditions, a number of respondents wished to stay in the private rental sector. Their reasons were various; some wished to remain in their old inner city neighbourhood with its familiar services and networks and, although eligible for public housing, did not want to be relocated to a small bedsit in the suburbs. Waiting lists are also long for public housing and no pets are allowed, an issue of particular importance to respondents. The authors comment that the disadvantages of the private rented sector could be reduced through rent control, enforced standards of repairs and maintenance, greater security and an increase in rent relief. 
The final group of older women lived in public housing and in many ways their comments mirror those of the private renters. The two main areas of complaint were the size of their accommodation and its location. In terms of size it appears that the bedsitter is the standard form of public housing for the elderly in Australia, and yet many women commented on the need for an extra bedroom. In terms of location, many felt isolated as they had been relocated away from their former neighbourhood and often had to travel long distances on inadequate public transport to reach friends or attend a doctor. The authors comment that the need to locate housing projects for older people within familiar neighbourhoods is now being taken on board by the authorities. Apart from these concerns, respondents also commented on a lack of privacy, poor security, problems of maintenance and repair, and the cost of heating, all of which serve to paint a rather poor picture of the public housing sector. However, the main advantages of such housing lie in the low rental costs, which are fixed not to exceed $20 \%$ of income, and the security of tenure.

In concluding, the authors comment on the wide variety of housing circumstances in which single older women live, demonstrating how low income and inexperience with housing matters can lead to an impoverished lifestyle. They list the following important housing needs for older women: 'adequate size of accommodation, privacy, security, proximity to transport and amenities, individual control, good heating, the possibility of entertaining and having friends to stay, keeping pets and individual autonomy'.

\section{COMMENT}

This paper provides useful empirical material concerning older women's housing circumstances within a variety of settings. The authors raise a wealth of issues at both the practical and personal levels which not only have implications for the design and organisation of housing for older people across the sectors, but also demonstrate how housing conditions can directly reflect women's roles throughout life and the need for women to vocalise their housing needs as they get older.

A. L. Sweaney, J. F. Pittman, Jr. and J. E. Montgomery, The influence of marital status and age on the housing behaviour of older Southern women. Journal of Housing for the Elderly, 2 (3) (1984), 25-36.

In contrast to the above article, this paper tells us little of the actual housing circumstances of older women, instead the focus is on deter- 
minants of housing behaviour. While growing older is associated with the increased likelihood of health problems which may exacerbate housing change, marital status is most likely to mean widowhood which may also lead to a reassessment of lifestyle. The authors, therefore, set out to test the impact of age and material status in relation to the housing behaviour of two groups of older women - those who are widowed and those who are married - living in the Southern States of the USA.

The study focuses on two samples of women $5^{\circ}$ years and over: 227 widowed female household heads and 227 married females living with their spouses. All respondents were involved in a larger study of housing for low and moderate income families. The widows were slightly older than the married women, and a greater number had an income below the poverty level. In terms of race, more non-whites were widowed than whites. However, educational level was similar for both groups.

One- and two-way analysis of variance is used to determine the effects of widowhood and age on a range of dependent variables concerning housing behaviour. These include: current housing situation defined in terms of six physical characteristics of respondents' housing (three characteristics relate to house size, three relate to house quality); housing costs (actual expenses and utility costs); mobility (years in present dwelling); housing satisfaction (more or less satisfied); decision making (extent to which children helped make housing decisions) and consumer acceptance (attitudes towards six dwelling types).

The results show that marital status is related to a number of aspects of housing behaviour. Widows live in smaller properties, which are in poorer condition than those of married couples and have fewer energy features. They pay less for their housing than married respondents; are less satisfied with their current housing, are likely to involve their children in housing decisions more often than did married respondents, and prefer apartment living. In terms of age, older respondents live in smaller properties although analysis shows that marital status is a more robust predictor than age in terms of housing size. However, age is a good determinant of geographic mobility, i.e. the older age groups had lived longest in their present dwellings, and older respondents were more likely than younger respondents to ask their children to help make housing decisions. There is also evidence that older respondents experience lower housing costs than younger respondents and are less accepting of certain housing alternatives described here as conventional housing, retrofitted and active solar dwellings.

In order to extend their analysis the authors also introduce a number of other independent variables: income, race, education, location of 
home (rural, suburban, town) and disability, alongside age and marital status. They use multiple regression to determine influence on housing behaviour, and their analysis shows the significance of other factors which are often of greater importance than age or marital status. For example both income and education are related to housing size; race and education are predictors of housing costs, and race and income relate to housing satisfaction. The authors comment that without the introduction of other variables they may have concluded that both age and marital status were highly important predictors of a range of housing behaviours instead of being 'reasonable predictors'. The introduction of other variables indicates that marital status is not as robust as age in this analysis and they comment that 'the effects of widowhood are superseded by those of other demographic factors'. However, they suggest that both variables may assume greater importance in extreme old age.

\section{COMMENT}

Whilst this article pays little attention to gender differences or the context in which widowhood and married women's housing behaviour may vary, it does draw our attention to the complexity of housing behaviour and the inter-relationship of factors such as income, race and education alongside age and material status which are often overlooked. The article, therefore, provides a useful stimulus for further research.

\section{NOTES}

I Brion, M. and Tinker, A. Women in Housing: Access and Influence. The Housing Centre Trust, London, ig8o.

2 Matrix. Making Space: Women and the Man-Made Environment. Pluto Press, London, 1984 .

a Willcocks, D. M., Peace, S. M. and Kellaher, L. A. Private Lives in Public Places. Tavistock Publications, London, 1986.

- See also Willcocks, D. M. 'Gender and the care of elderly people in Part III accommodation', paper presented at the Annual Conference of the British Society of Gerontology, Liverpool, September 1983 .

Centre for Environmental and Social Studies in Ageing, The Polytechnic of North London 